\title{
ALIENS AT THE BORDER AND CADAVERS IN THE FIELD: A MOLECULAR TECHNIQUE FOR SPECIES IDENTIFICATION
}

\author{
K.F. ARMSTRONG ${ }^{1}$, C.M. CAMERON ${ }^{1}$, \\ E.R. FRAMPTON ${ }^{2}$ and D.M. SUCKLING ${ }^{3}$ \\ ${ }^{1}$ Department of Entomology and Animal Ecology, \\ Lincoln University, Canterbury \\ ${ }^{2}$ MAF Regulatory Authority, P.O. Box 24, Lincoln, Canterbury \\ ${ }^{3}$ HortResearch, P.O. Box 51, Lincoln Canterbury
}

\begin{abstract}
Immature life stages of fruit flies (Diptera: Tephritidae) and leafroller moths (Lepidoptera: Tortricidae) can not be readily distinguished by phenotype. The need to identify these groups originated for different primary reasons but identification has been achieved using a common molecular approach. Restriction fragment length polymorphism (RFLP) detected in polymerase chain reaction (PCR) amplified ribosomal DNA (rDNA) provides a rapid diagnostic test for several of these species across a broad taxonomic range, irrespective of life stage or tissue quality. Application of this technique to identify fruit fly specimens intercepted at the border and parasitised leafroller cadavers in the field is presented.

Keywords: ribosomal DNA, PCR-RFLP, species identification, fruit flies, leafroller moths
\end{abstract}

\section{INTRODUCTION}

Accurate identification of pest organisms is essential for efficient quarantine practices and the development and deployment of pest management strategies (Hawksworth 1994). For insect pests, it is often the immature life stages that cause damage and are important for their control or detection but, in contrast to the adults, immature life stages can be difficult or impossible to identify to the species level. Of significant threat to the New Zealand horticultural industry are fruit flies and leafrollers. The need to accurately identify immature life stages of these groups to the species level has arisen for different reasons, but the means of doing this for both groups has been achieved using the same molecular approach.

The quarantine risk to New Zealand of economically important fruit flies species has resulted in the implementation of strict procedures to minimise the risk of their introduction (Cowley and Frampton 1989). There are about 250 pest species of fruit fly (White and Elson-Harris 1992) which present different degrees of risk to New Zealand depending on their host and climatic preferences. The risk associated with their likely establishment here determines the quarantine action, i.e. to treat, re-ship or destroy imported commercial consignments, or implementation of an eradication procedure. However, often it is the larvae or eggs that are intercepted at the border in fruit of commercial consignments or accompanying overseas travellers. Frequently these specimens cannot be identified beyond the family level. Rearing through to adults can be pursued in some cases, but this is slow and often unsuccessful. This significantly limits the data contributing to quarantine action decisions or to the assessment of the actual security risk presented at the border. Therefore a reliable and rapid $(<48 \mathrm{~h}, \mathrm{~K}$. Nalder pers. comm.) method to supplement current routine quarantine practices is desirable.

In contrast, the presence of leafrollers in New Zealand requires significant pest management effort to maintain orchard health and meet trading partners import requirements. The improvement of biocontrol in IPM programmes would be beneficial, to help limit pesticide applications yet still satisfy overseas market requirements. Many

Proc. 50th N.Z. Plant Protection Conf. 1997: 316-321 
species of larval parasitoids (especially Australian members of Hymenoptera: Braconidae) are commonly reared through from the six most abundant species of native or introduced leafroller larvae retrieved from orchards (Wearing et al. 1991). Their taxonomy has recently been sufficiently resolved (Austin and Dangerfield 1992) to enable reliable identification and biological study. However, a major barrier to assessing their ecological relationship with the host remains the inability to identify, from the cadaver, which species of leafroller has been parasitised. This is particularly true for areas with high levels of sympatry.

The development of a common molecular diagnostic tool for these two different applications has been pursued based on the PCR amplification and restriction analysis of the ribosomal DNA (rDNA). This basic method has been reported previously for fruit flies (Armstrong et al. 1997). Here we present the practical application of the technique for fruit flies and its development to date for use with leafrollers.

\section{Fruit flies}

\section{MATERIALS AND METHODS}

Larvae detected in fruit during the Mediterranean fruit fly (Ceratitis capitata) alert at Mount Roskill during May, 1996 and larvae or eggs detected by routine screening of air passenger intercepted fruit were fixed in boiling water and then stored in $90 \%$ ethanol for transportation.

DNA extraction, PCR of the $18 \mathrm{~S}$ plus internal transcribed spacer (ITS) region and restriction analysis was carried out according to a previously published procedure (Armstrong et al. 1997). The PCR amplification of egg DNA was modified from that above, requiring 10-fold less DNA and two extra PCR cycles. Positive standards, using DNA from known species and of the same host and geographic range, were run concurrently for comparison with established restriction patterns (Armstrong et al. 1997).

\section{Leafrollers}

Laboratory-reared larvae ofEpiphyas postvittana (Walker),Planotortrixnotophaea, P.octo (Dugdale),P.excessana (Walker),Cnephasiajactatana, Ctenopseustis obliquana (Walker) and Ct. herana (Felder and Rogenhofer) were supplied live from Mount Albert Insect Rearing Group, reared through to third instar and frozen before use.E. postvittana was also obtained as dried cadavers from laboratory parasitised larvae (7-14 days postemergence of parasitoid). Field populations of all species, with the exception of $P$. notophaea (which is rare in orchards), were obtained from pheromone-trapped male moths (Suckling and Shaw 1990; Fosteret al. 1993), stored frozen on the sticky bases and then scraped off immediately prior to use.

For molecular analysis, larval tissue was digested in $500 \mu$ l proteinase K solution $(0.4$ $\mathrm{mg} / \mathrm{ml}$ in $10 \mathrm{mM}$ Tris, $1 \mathrm{mMEDTA} \mathrm{pH} 8.0,10 \mathrm{mM} \mathrm{NaCl}$ and $1 \% \mathrm{SDS}$ ) for $2 \mathrm{~h}$ at $50^{\circ} \mathrm{C}$. DNA was extracted using a high salt method (Montgomery and Sise 1990) for larvae and adults and a Prep-a-Gene (BioRad) method (Armstronget al. 1997) for the cadavers and resuspended in TE. DNA concentrations were estimated by agarose gel electrophoresis and optimised for PCR. PCR amplification of the ITS region was carried out in a GeneAmp PCR system 2400 (Perkin Elmer) using 0.84 U Expand High Fidelity polymerase (Boehringer Manheim), $1 \mathrm{x}$ Expand High Fidelity buffer, $2 \mathrm{mMMgCl}, 0.15$ $\mathrm{mM}$ dNTPs (Boehringer Manheim), $0.24 \mu \mathrm{M}$ each primer and $0.6 \mu 1 \mathrm{DNA}$ in a total volume of $15 \mu \mathrm{l}$. Negative reactions used TE to replace DNA. The thermal profile was $94^{\circ} \mathrm{C}$ for 2 min then 10 cycles of $94^{\circ} \mathrm{C} / 15 \mathrm{~s}, 54^{\circ} \mathrm{C} / 30 \mathrm{~s}, 68^{\circ} \mathrm{C} / 2$ min followed by 25 cycles of $94^{\circ} \mathrm{C} / 15 \mathrm{~s}, 54^{\circ} \mathrm{C} / 30 \mathrm{~s}, 68^{\circ} \mathrm{C} / 2 \mathrm{~min}$ plus $20 \mathrm{~s}$ extra each extension cycle and then a final extension of $5 \mathrm{~min}$ at $72^{\circ} \mathrm{C}$. PCR products $(2-6 \mu \mathrm{l})$ were digested in a $10 \mathrm{ml}$ reaction containing 3.5U restriction enzyme (Boehringer Manheim), 1x restriction buffer for 1.5 $\mathrm{h}$ at $37^{\circ} \mathrm{C}$. Restriction products were resolved on a $2 \%$ agarose gel (LE, Boehringer Manheim) electrophoresed for $2 \mathrm{~h}$ at $4.5 \mathrm{~V} / \mathrm{cm}$.

\section{Fruit flies}

\section{RESULTS}

Application of the molecular technique during the Mediterranean fruit fly alert in Mount Roskill in May 1996 provided confirmed identification of all the larvae, to which 
the technique was applied, as C. capitata (Table 1). Identifications were available within 12-24 h of their receipt and $36 \mathrm{~h}$ after their detection. During method development, identification of specimens from air passenger interceptions has also been largely successful (Table 1). This included a few specimens that could only be assigned to a species complex for which distinguishing rDNA molecular markers have not, as yet, been identified. In these cases, the component species of the complex were all high risk and therefore would have resulted in the same quarantine action. On occasion, parallel DNA analysis and rearing of different samples from the same interception was possible. Results of the molecular method agreed with the morphological key in all but one of these cases (Table 1 and footnote ${ }^{4}$ ) demonstrating reliability of the DNA technique.

\section{TABLE 1: Identification of fruit fly species from immature life stages.}

\begin{tabular}{lcccc}
\hline & No. intercepted & \multicolumn{3}{c}{ No. Postive identifications ${ }^{1}$} \\
& & DNA & MAF & DNA=rearing \\
\hline Mt Roskill alert & 85 & $74(74)$ & N/A & $1(1)$ \\
Passengerintercept. & 45 & $27(31)^{2}$ & $20(42)^{3}$ & $11(12)^{4}$ \\
\hline
\end{tabular}

${ }^{1}$ Numbers in parentheses were the total number available.

${ }^{2}$ Of the 4 not identified, one was eggs before protocol appropriately optimised, one was degraded/contaminated from boiled breadfruit and two produced restriction patterns of species not included in protocol development. Of those identified, four were dead on interception. Multiple specimens were analysed where possible for each interception.

${ }^{3}$ Of the 22 not identified, 5 were dead on interception. Rearing was required for 18 of those identified.

${ }^{4}$ One sample, provided as eggs to Lincoln and not identified, was successfully reared by MAF from larvae in the same interception.

\section{Leafrollers}

Laboratory-reared larvae were initially employed to test several combinations of universal primers for amplification of the ITS region. Optimal amplification for all species was achieved with primers ITS5 (White et al. 1990) and FFB (TATGCTTAAATTCAGGGGGT, designed for use with tephritids) generating a 1-1.6 $\mathrm{kb}$ fragment encompassing the ITS1/5.8S/ITS2 region. Preliminary screening with 11 restriction enzymes indicated that there were no restriction sites for Apa I, Ban I or Bam $\mathrm{HI}$ in any of the species. With $\mathrm{Cfo}$ I the differences in restriction patterns between species were apparent but the small sizes of the fragments were not resolved clearly enough to be quantified. For the remaining enzymes, gel electrophoresis restriction patterns, similar to those documented for fruit flies (Armstrong et al. 1997), were used to construct a haplotype chart (Table 2). Greatest resolution was achieved by two enzymes, Dde I and Hinf I, each producing five restriction patterns for the seven species; $P$. excessana could not be distinguished from $P$. octo, nor $C$. herana from C. obliquana. Preliminary analysis using field-trapped male moths indicates that these restriction markers are stable between populations. These specimens have been a convenient source of positively identified wild specimens, especially for the Ctenopseustis and Planotortrix sibling pheromone taxa. The DNA obtained from cadaverous tissue required less optimisation to amplify via PCR than that from the adults, possibly due to the more efficient removal of impurities by the Prep-a-Gene method of DNA extraction. Restriction patterns were the same as those obtained with the laboratory reared $E$. postvittana larvae.

TABLE 2: Restriction haplotypes ${ }^{1}$ assigned to leafroller species.

Species $^{2}$

Alu I Ban II Dde I Hae III Hinf I Rsa I Sau 3A 
A

$550,550,140,160$

\section{P. notophaea}

$\mathrm{B}_{1}$

670,400

$$
\mathrm{A}_{1}
$$

670,410

B
600,430

$\mathrm{B}_{1}$

610,410

B
$440,390,200,150$

B

1080

A

720,430

A

$50,350,340,150$

P. octo

$\mathrm{B}_{2}$

640,400

$\mathrm{A}_{2}$

640, 410

C
$430,320,250$

$\mathrm{B}_{2}$

$580,410,50$

C
$700,200,150$

B

1080

$\mathrm{B}_{2}$

$590,280,200$

P. exessana

$\mathrm{B}_{2}$

640,400

$\mathrm{A}_{2}$

640, 410

C

430,320,250

$\mathrm{B}_{2}$

$580,410,50$

C

B

1080

$\mathrm{B}_{2}$

$590,280,200$

Cn. jactatana

C B

D

730,330,210

C

720,530

D

1000,140,160

C

320,500

C

550,370

Ct. obliquana

$\mathrm{B}_{3}$

$\mathrm{A}_{1}$

670,410

E

440,320,270

$\mathrm{B}_{3}$

620,420

E

400,330,200,150

B

1080

D

610,430

Ct. herana

$\underset{670,410}{\mathrm{~A}_{1}}$

$\underset{40,320,270}{\text { E }}$

$\mathrm{B}_{3}$

620,420

$\underset{400,330,200,150}{\text { E }}$

$\mathrm{D}$

610,430

${ }^{1}$ Haplotypes are constructed from the combination of restriction enzyme patterns. Different letters indicate a different pattern. The same letters with different numbers indicate subtle length variation of the same pattern. Fragment sizes were approximated by comparison to a 100 bp standard DNA ladder (Gibco BRL).

2 Pheromone-trapped moths obtained for E. postvittana (Pukekohe, Morrinsville, Te Puke, Hawkes Bay, Lincoln), P. octo (Pukekohe, Katikati, Te Puke, Hawkes Bay, Lincoln, Alexandra), P. excessana (Morrinsville, Katikati, Riwaka, Nelson), Cn. jactatana (Te Puke, Riwaka, Nelson, Lincoln), Ct. obliquana (Pukekohe, Morrinsville, Te Puke, Hawkes Bay, Riwaka, Alexandra) and Ct. herana (North Auckland, Riwaka, Nelson, Lincoln).

\section{DISCUSSION}

The PCR-RFLP method used in this study has provided a rapid diagnostic procedure with markers that are relatively simple to interpret. Distinguishing species between and within genera is possible for otherwise unidentifiable specimens of fruit flies and leafrollers. For fruit flies, the method currently provides 28 diagnostic restriction haplotypes for 34 tephritid species (Armstrong et al. 1997; Armstrong and Cameron unpubl. data). This includes 19 haplotypes for 26 of the species tested that are also listed in the Biosecurity (Notifiable Organisms) Amendment Order (1997). For quarantine purposes, this data has greatly improved the information contributing to (a) a response situation and (b) the ongoing assessment of the security risk presented by fruit flies to New Zealand. For the leafrollers, the use of cadaverous material does not present a problem for this technique, but many more restriction enzymes need to be tested before making conclusions about its utility.

Attributes of the ribosomal gene complex (Hillis and Dixon 1991) make it an ideal source of species markers in many organisms (e.g. Fenton et al. 1995). Previous work with the greenheaded and brownheaded leafrollers identified genus and species specific markers in the $28 \mathrm{~S}$ region of rDNA (Sin et al. 1995). Using that technique C. obliquana could be distinguished from $C$. herana but the difference between $P$. octo 
and $P$. excessana was ambiguous. In any event, the protocol was not appropriate for use with cadaverous material. In the present study, using small windows of DNA sequence, i.e. restriction sites, as markers minimises the effect of population-level length variation (cf Vogler and DeSalle 1994). Ambiguities that may arise from mutation at a specific restriction site are minimised by screening several different restriction site sequences. However the current method is limited in distinguishing sibling species, such as those recently described within theBactrocera $(B$.) dorsalis complex for fruit flies (Drew and Hancock 1994) and the pheromone-based taxa within the greenheaded and brownheaded leafroller groups (Foster et al. 1991). A full sequence analysis of the ITS is required to confirm this. Alternative DNA regions could be considered. A recent sequence analysis of the cytochrome oxidase (CO) genes (mitochondrial DNA) in leafrollers (R. Newcombe unpubl. data) has identified potentially useful restriction site polymorphism's that separate the seven species in this present study. This gene region has also been used for the identification of lepidopteran sibling species within the spruce budworm complex (Sperling and Hickey 1995). However, the PCR-RFLP analysis in that study detected population-level variation, emphasising the need for extensive population screening to test robustness of $\mathrm{CO}$ markers delineating recently diverged species.

This study has demonstrated the benefits of a molecular tool for supplementing current methods of species identification from immature life stages. The procedure is more rapid and reliable than rearing and offers the opportunity to use parasitised/dead samples, specimens of any life stage and reassessment of old preserved samples. Current research includes a sequence analysis of the ITS in fruit flies and design of tephritidspecific PCR primers to reduce complications from contaminating host plant, parasitoid or fungal DNA (Fenton et al. 1994). A PCR-RFLP analysis of the cytochrome oxidase genes in leafrollers will also be pursued.

\section{ACKNOWLEDGEMENTS}

We are grateful to Kay Chadfield for forwarding the Ministry of Agriculture's rearing results for border fruit fly interceptions and also to members of the HortResearch Environmental Entomology group for pheromone trap leafroller specimens and Graham Burnip for discussion and supply of lightbrown apple moth cadavers.

\section{REFERENCES}

Armstrong, K.F., Cameron, C.M. and Frampton, E.R., 1997. Fruit fly (Diptera: Tephritidae) species identification: a rapid molecular diagnostic technique for quarantine application. Bull. Entomol. Res. 87: 111-118.

Austin, A.D. and Dangerfield, P.C., 1992. Synopsis of Australasian Microgastrinae (Hymenoptera: Braconidae), with a key to genera and description of new taxa. Invert. Taxon. 6: 1-76.

Cowley, J.M. and Frampton, E.R., 1989. Significance of and monitoring for alien fruit flies (Tephritidae). Proc. 42nd N.Z. Weed and Pest Control Conf.: 200-203.

Drew, R.A.I. and Hancock, D.L., 1994. The Bactrocera dorsalis complex of fruit flies (Diptera: Tephritidae: Dacinae) in Asia.Bull. Entomol. Res. Supplement Series 2.

Fenton, B., Birch, A.N.E., Malloch, G., Woodford, J.A.T. and Gonzalez, C., 1994. Molecular analysis of ribosomal DNA from the aphidAmphorophora idaei and an associated fungus. Ins. Mol. Biol. 3: 183-189.

Fenton, B., Malloch, G., Jones, A.T., Amrine Jr., J.W., Gordon, S.C., A'Hara, S., McGavin, W.J. and Birch, A.N.E., 1995. Species identification of Cecidophyopsis mites (Acari: Eriophyidae) from differentRibesspecies and countries using molecular genetics. Mol. Ecol. 4: 383-387.

Foster, S.P., Dugdale, J.S. and White C.S., 1991. Sex Pheromones and the status of the greenheaded and brownheaded leafroller moths in New Zealand. N.Z. J. Zool. 18: 63-74.

Foster, S.P., Steven, D., McKenna, C. and Muggleston S.J., 1993. Sex pheromones of two New Zealand tortricid moths, Cnephasia jactatana andMerophyas leucaniana. N.Z. J. Zool. 20: 81-88.

Hawksworth, D.L., 1994. The Identification and Characterisation of Pest Organisms. 
Wallingford: CAB International.

Hillis D.M. and Dixon M.T., 1991. Ribosomal DNA: Molecular evolution and phylogenetic inference. Quarterly Rev. Biol. 66: 411-453

Montgomery, G.W. and Sise, J.A., 1990. Extraction of DNA from sheep white blood cells. N. Z. J. Agric. Res. 33: 437-441.

Sin, F.Y.T., Suckling, D.M. and Marshall, J.W., 1995. Differentiation of the endemic New Zealand greenheaded and brownheaded leafroller moths by restriction fragment length variation in the ribosomal gene complex.Mol. Ecol. 4: 253-256.

Sperling, F.A.H. and Hickey, D.A., 1995. Amplified mitochondrial DNA as a diagnostic marker for species of conifer-feeding Choristoneura (Lepidoptera: Tortricidae). Can. Entomol. 127: 277-288.

Suckling, D.M. and Shaw, P.W., 1990. Preliminary trials of mating disruption of lightbrown apple moth in Nelson. Proc. 43rd N.Z. Weed and Pest Control Conf: 311-316.

Vogler, A.P. and DeSalle, R., 1994. Evolution and phylogenetic information content of the ITS-1 region in the tiger beetleCicindela dorsalis. Mol. Biol. Evol. 11:393-405.

Wearing, C.H., Thomas, W.P., Dugdale, J.S. and Danthanarayana, W., 1991. Tortricid pests of pome and stone fruits, Australian and New Zealand species. Pp 453-469.In: Tortricid Pests: their Biology, Natural Enemies and Control. L.P.S van der Geest and H.H. Evenhuis, (Eds). Elsevier, Amsterdam.

White, I.M. and Elson-Harris, M.M., 1992. Fruit Flies of Economic Importance: Their Identification and Bionomics. CAB International.

White, T.J., Bruns, T., Lee, S. and Taylor, J., 1990. Amplification and direct sequencing of fungal ribosomal RNA genes for phylogenetics. Pp 315-322.In: PCR Protocols: a Guide to Methods and Applications. M.A. Innis and D.H. Gelfand, J.J. Sninsky and T.J. White (Eds). Academic Press Inc., San Diego. 